\section{Unsuspected acquired haemophilia in a patient with myocardial infarction}

\author{
P W X Foley MB MRCP ${ }^{1}$ D Pepperell BM BSc $^{2}$ \\ Rashid Kazmi MRCP MRCPath ${ }^{2}$ \\ N P Curzen PhD FRCP ${ }^{1}$
}

J R Soc Med 2004;97:542-543

In a patient with acute myocardial infarction, evidence of impaired clotting demands urgent attention.

\section{CASE HISTORY}

A man of 78 was admitted with an acute coronary syndrome. His medical history included coronary and cerebral vascular disease, severe chronic obstructive airways disease, type 2 diabetes and hypercholesterolaemia but no bleeding problems.

On examination he was haemodynamically stable. No cutaneous bruising was noted. Troponin I was $1.59 \mathrm{ng} / \mathrm{mL}$ (normal less than 0.15). The electrocardiogram showed sinus rhythm with no acute changes. He was treated with enoxaparin (1 mg/kg twice daily), clopidogrel, aspirin, a statin and anti-anginal therapy. Initial blood results showed a normal full blood count but his activated partial thromboplastin (APTT) ratio was raised at 4 (normal $0.80-1.20)$. No explanation for this result was sought at the time.

The patient was listed to undergo coronary angiography and revascularization but on the day of the proposed procedure extensive bruising appeared over his left arm and abdomen (Figure 1). The enoxaparin was stopped; however, the APTT ratio was still high at 3.40. The factor VIII concentration was then found to be $<1 \mathrm{U} / \mathrm{dL}$ (normal 50-150) and acquired haemophilia A was diagnosed. The inhibitory titre was 35 Bethesda units (normal 0). On haematological advice he was given prednisolone $(1 \mathrm{mg} / \mathrm{kg})$. The haemoglobin dropped to $8 \mathrm{~g} / \mathrm{dL}$ and recombinant factor VIIa was started at $90 \mu \mathrm{g} / \mathrm{kg}$ 2-hourly along with red cell concentrate and platelet transfusions. The aspirin was stopped. During this time the patient continued to experience chest pain, with

${ }^{1}$ Wessex Cardiac Unit and ${ }^{2}$ Department of Haematology, Southampton University Hospital, Southampton SO16 6YD, UK

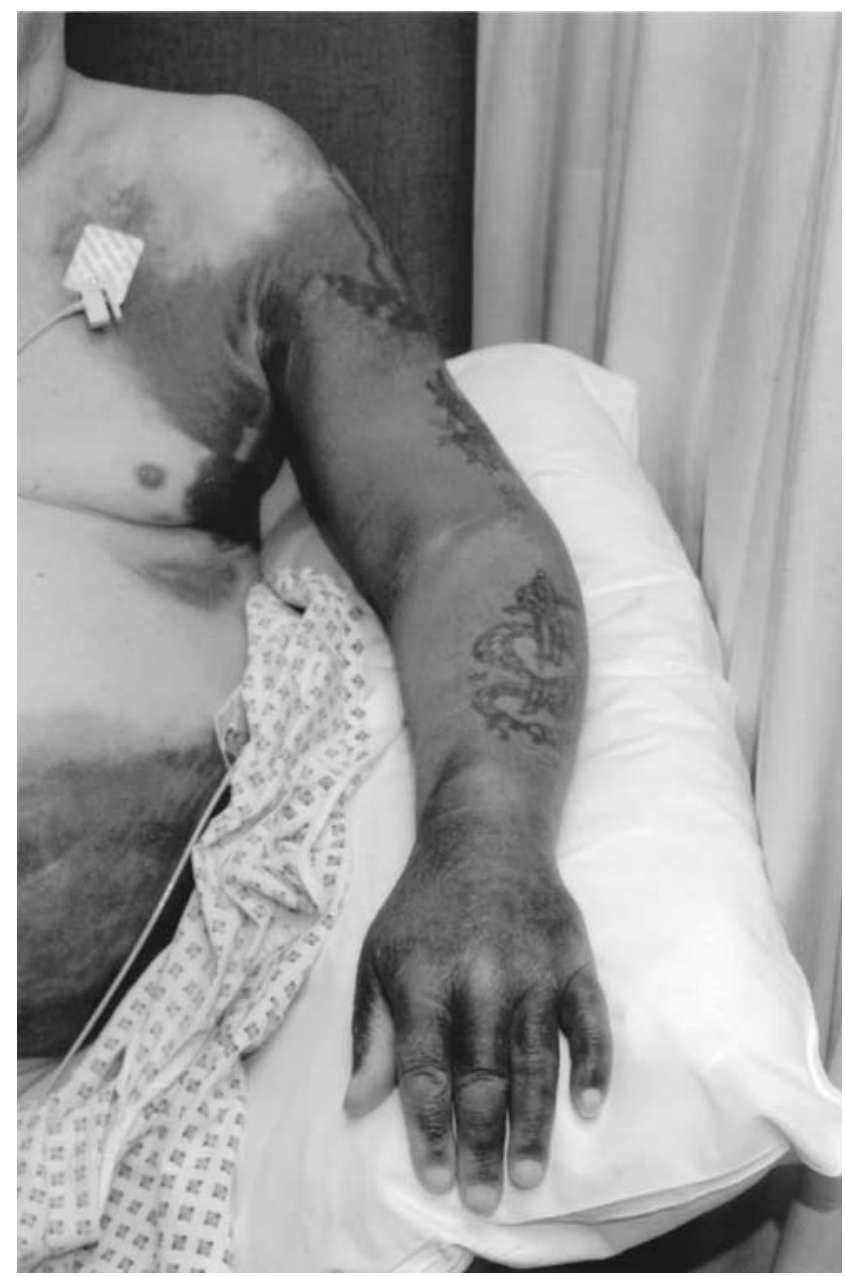

Figure 1 Bruising on upper limb and abdomen

ischaemic electrocardiographic changes, but this was treated medically.

The factor VIIa was stopped after 48 hours. Treatment with prednisolone was continued, and when there was no adequate factor VIII response he was given intravenous immunoglobulins (Vigam) $0.4 \mathrm{~g} / \mathrm{kg}$ for five days. Oral cyclophosphamide $2 \mathrm{mg} / \mathrm{kg}$ daily was added. His condition improved gradually and he was discharged. After two weeks on prednisolone and cyclophosphamide his factor VIII was $12 \mathrm{U} / \mathrm{dL}$.

\section{COMMENT}

Acquired haemophilia A results from production of autoantibodies, typically $\operatorname{IgG}$, that partly or completely inhibit the coagulant activity of factor VIII. The estimated incidence is 1 to 4 per million per year. ${ }^{1}$ Factor VIII inhibitors can sometimes occur in healthy individuals with normal factor VIII levels and one study showed 17\% of healthy blood donors to have a natural factor VIII neutralizing antibody. About $50 \%$ of cases of acquired 
haemophilia are associated with autoimmune diseases, malignancies or drug administration. ${ }^{2}$ Clinically it is characterized by spontaneous and often severe bleeding in patients with no history of a bleeding diathesis. Typically there is cutaneous and soft tissue bleeding with muscle haematomas. Other frequent manifestations are haematuria and gastrointestinal bleeding, while intracerebral haemorrhage can also occur. Management involves treatment of active bleeding and suppression of the inhibitory antibody. Options for the treatment of bleeding episodes are human or porcine factor VIII concentrate, activated prothrombin complex concentrates and recombinant human activated factor VII. ${ }^{3}$ Immunosuppressant agents that have been employed for eradication of the inhibitor include prednisolone, cyclophosphamide, azathioprine and cyclosporin. Treatment with intravenous immunoglobulins has been successful and the anti-CD20 antibody rituximab has also been found effective. ${ }^{4,5}$ Patients refractory to conventional immunosuppressive therapy have responded to treatment with 2-chlorodeoxyadenosine. ${ }^{6}$

This case illustrates the importance of noting and acting upon abnormalities of baseline blood tests. The APTT was abnormal early in his admission but the importance of the abnormal ratio was not appreciated until the patient developed extensive bruising. If he had undergone angiography and coronary stenting the bleeding might well have been catastrophic since he would have been treated with aspirin, clopidogrel, heparin and the glycoprotein IIb/ IIIa inhibitor abciximab.

\section{REFERENCES}

1 Evans EN, Majer RV. Acquired haemophilia: an important but often unrecognised cause of bleeding in elderly people. BMJ 1995;311:679-81

2 Baudo F, de Cataldo F. Acquired hemophilia: a critical bleeding syndrome. Haematologica 2004;89:96-100

3 Arkin S, Blei F, Fetten J, et al. Human coagulation factor FVIIa (recombinant) in the management of limb-threatening bleeds unresponsive to alternative therapies: results from the NovoSeven emergency-use programme in patients with severe haemophilia or with acquired inhibitors. Blood Coagul Fibrinolysis 2000;11:255-9

4 Kain S, Copeland TS, Leahy MF. Treatment of refractory autoimmune (acquired) haemophilia with anti-CD20 (rituximab). Br J Haematol 2002;119:578

5 Wiestner A, Cho HJ, Asch AS, et al. Rituximab in the treatment of acquired factor VIII inhibitors. Blood 2002;100:3426-8

6 Sallah S, Wan JY. Efficacy of 2-chlorodeoxyadenosine in refractory factor VIII inhibitors in persons without hemophilia. Blood 2003;101:943-5

\section{Appendicitis after appendicectomy}

\section{James Clark MB BS N Theodorou MS FRCS}

J R Soc Med 2004;97:543-544

CLINICAL SECTION 13 JANUARY 2004

Appendicitis after appendicectomy usually results from inflammation of an incompletely removed proximal portion of the appendix - stump appendicitis. We present a less common, distal, variant.

\section{CASE HISTORY}

A woman aged 34 was initially seen after two days of central abdominal pain radiating to the right iliac fossa. She was pyrexial with a leukocytosis and the clinical findings supported a diagnosis of acute appendicitis. Appendicectomy was performed conventionally without burial of the appendix stump. The operation was described as difficult and a 'ruptured' appendix was removed with insertion of a drain. Appendicitis was confirmed histologically in the fragments presented. The patient made a slow but uneventful recovery and was discharged after ten days.

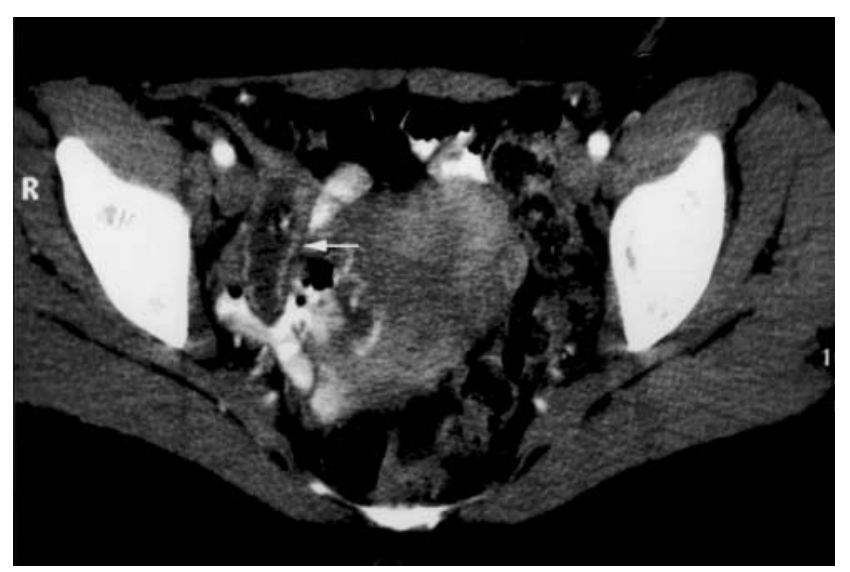

Figure 1 CT scan showing fluid-filled mass in right pelvis

Two months after discharge she returned with abdominal discomfort beneath the wound scar, which

Gastrointestinal Surgical Department, Charing Cross Hospital, London, UK

Correspondence to: Dr James Clark, Floor 8E, room 01, Charing Cross Hospital, Fulham Palace Road, London W6 8JQ, UK 